\title{
JOVELLANOS: O ILUMINISMO ESPANHOL E O PROBLEMA AGRĀRIO
}

\author{
Leopoldo Collor Jobim \\ da Fundação Nacional \\ Pró-Memória
}

O movimento iluminista espanhol tem merecido várias interpretações. Ortega y Gasset nega, de forma radical, sua existência, afirmando que a Espanha saltara esse século, razão pela qual propõe que a sua época retome aqueles principios $\curvearrowright$ valores. Outros historiadores acreditam o contrário, ou seja, que a Espanha moderna é fruto dessa época.

Jean Sarrailh1 privilegia a influência estrangeira exercida através de viajantes, contrabando de livros, ação de ministros estrangeiros e contatos pessoais com os "philosophes", atribuindo o movimento à ação de uma minoria esclarecida que, segundo ele, não coincide necessariamente com a elite sócio-econômica. Para outros historiadores, os iluministas espanhóis, embora indiscutivelmente inspirados em modelos estrangeiros, estavam imbuidos de um passado nacional que nunca trairam. Recentemente está sendo reinterpretado o papel dos "afrancesados", ou seja, os reformadores diretamente ligados à França, até pouco considerados traidores da pátria.

Ainda outra corrente de interpretação nega uma influência estrangeira decisiva, encontrando no século XVII espanhol as raizes da crítica ao barroco e à cultura tradicional por ele representado. A verdade é que ao configurarem-se, em meados do século XVIII, as condiçōes politicas para o reformismo, encontram equipes já formadas para realizar a obra de reestruturação.

O início do período reform'sta coincidiu com o início do século XVIII e com a substituição da dinastia Habsburgo pela Bourbon: pode-se mesmo falar em reformismo borbônico. O século das Luzes na Espanha começa a apagar-se com o advento de Carlos IV (1789) e com a Revolução Francesa. A radicalização provocada por esse acontecimento e o temor de 
que se alastre para o sul dos Pirineus faz com que as idéias reformistas sejam freiadas e a reação desfaz alguns aspectos da obra já empreendida.

Os reis foram auxiliados no projeto de renovação por alguns ministros e colaboradores muito competentes como, no reinado de Carlos III (1759-1788) - justamente considerado o auge do movimento - Aranda, Floridablanca e Camponeses. Jovellanos, se bem que tenha atuado muito nesse periodo, foi ministro mais tarde, já no reinado de Carlos IV.

O movimento iluminista ia naturalmente adquirindo aspectos particulares em diferentes momentos e ambientes históricos. Seus aspectos essenciais, ou seja, o prestígio ilimitado da razão e do método empírico, e a crença no progresso, que se tornaria inevitável a partir do momento em que os homens regulassem suas relações pela razão, também se manifestam na Espanha, embora de maneira especifica.

Os iluministas desse pais projetam a fé no progresso a partir da aceitação da decadência de sua pátria, e o ataque à tradição justifica-se plenamente desde que se lhe oponha a razão. Por outro lado, a crítica à monarquia absoluta, como proposta por Montesquieu ou por Rousseau, não ocorre ali; na Espanha o poder real é valorizado e permanece inquestionável. A sociedade exige da Coroa que assuma o papel de déspota esclarecido. Em relação ao catolicismo, atacam-se os abusos de costumes do clero ou a concentração de riqueza, sobretudo fundiária, em suas mãos, sem se consubstanciar, no entanto, numa proposta atéia ou especificamente anti-clerical.

Para a disseminação dos valores iluministas contribuem muito as Sociedades Econômicas do País, espalhadas pelas diversas províncias.

A situação da Espanha no século XVIII, tanto no aspecto social como econômico, é muito grave. Se bem que durante esses cem anos a população passa de 8 para $11.500 .000^{2}$, o campo permanece em grande parte despovoado. Tanto os viajantes estrangeiros como os "esclarecidos" espanhóis ${ }^{3}$, que realizam viagens pelo interior para conhecer a realidade nacional - entre os quais Jovellanos -, espantam-se com a miséria, a ignorância, a falta de higiene e 0 analfabetismo da massa rural. As tentativas de reforma esbarram na rotina e superstição. Os Diários 4 de Jovellanos contêm reiteradas alusões à passividade e resistência à transformação. 
A aristocracia e o clero são proprietários do país; em algumas províncias onde se mantém o regime de pequena propriedade (Astúrias e Pais Basco) a situação é mais próspera. A sorte do povo das cidades é a mesma dos camponeses miséria, fome e doença, e Jovellanos aponta entre os fatores para esse estado de coisas "o excesso de riqueza e o abuso das aquisições (de terras)" da Igreja5.

Com exceção da Catalunha, a indústria praticamente inexiste, apesar das preocupações de alguns espanhóis em estimular esse setor de economia6. Mas a preocupação fundamental é indiscutivelmente a agricultura, conforme, evidenciam os numerosos informes, pareceres, decretos reais, leis agrárias e tentativas de reforma produzidas na segunda metade do século. Jovellanos, aludindo a este movimento de idéias, chama-o de "saudável fermentação, pois estes clamores são o melhor agouro para a prosperidade e o restabelecimento da agricultura"7.

Embora na prática o resultado dessa "fermentação" seja reduzido, o problema é ventilado, e abandonam-se as concepções herdadas da Idade Média e as tradições comunalistas; Jovellanos vai ser o primeiro a questionar o problema da propriedade da terra, embora todos se queixem das regulamentações absurdas e contraproducentes, herdadas de tempos remotos.

Um exemplo dos monopólios e privilégios, que apesar de terem perdido sua utilidade, não foram revogados, já que foram incorporados pelos grandes grupos econômicos, é a Mesta. Esta associação de criadores de carneiro em regime de transumância pode, durante alguns séculos, conciliar os interesses de pequenos, médios e grandes criadores, viabilizando a exportação da valiosa lã merino. A partir do século XVII, a Coroa passa a defender seus interesses, garantindo a sua expansão em detrimento da agricultura. Em troca dessa proteção, a Mesta paga à Coroa pesados impostos. No século XVIII é muito atacada, sendo considerada responsável pelo deflorestamento e pelo atraso da agricultura em geral, já que entre os "monstruosos e injustos" e "exorbitantes privilégios"8 que reunira figura à proibição de cercar os pastos comunais e de transformar as terras de pastoreio em plantio.

Jovellanos posiciona-se enfaticamente contra "este corpo, sempre vigilante na solicitude de privilégios e sempre bastante poderoso para 
os obter e aumentá-los;... (esses) privilégios são duvidosos em sua origem, abusivos em seu cumprimento, perniciosos em seu objeto e destrutivos do direito de propriedade;... (a Mesta constitui) uma autoridade opressiva e tão forte para oprimir os fracos como débil para freiar os poderosos." 9

O surto de preocupação com a agricultura deve-se também à expansão demográfica que exige maior quantidade de alimentos. Para aumentar a produção, novas plantas são introduzidas e realizam-se alguns grandes projetos de irrigação. Durante todo o século os preços em geral sobem, assim como o preço da terra, e tenta-se evitar um aumento excessivo do valor dos arrendamentos. Os progressos, sobretudo no reinado de Carlos III, são sensiveis, embora logo tenham esbarrado nos grandes interesses e no conservadorismo das autoridades locais.

Em 1761 o Conselho de Castela, órgão que traça as diretrizes políticas para o Rei, posiciona-se contra a Mesta, determinando que as vilas e municípios possam dispor das terras comunais; em 1766, através de Provisão Real, as terras devolutas da Estremadura são distribuidas a quem pudesse cultiválas; em 1767 confia-se a Olavide a inovadora experiência de colonização da Sierra Morena; em 1785 proibe-se, em certas circunstâncias, expulsar os arrendatários das terras que trabaIham; em 1788 permite-se cercar os vinhedos, hortas e pomares, mantendo-se, entretanto, a proibição para os grãos. Jovellanos exclama a respeito dos mesmos: "porque o primeiro apoio da subsistência pública, e o primeiro nervo da agricultura merece menos proteção que o vinho, as hortaliças e as frutas, que abastecem geralmente o luxo?"10. Em 1795 distribuem-se lotes de bens comunais para os camponeses que tenham recursos para cultivá-los.

A essas medidas práticas da Coroa correspondem estudos teóricos, ou "informes"11, a partir dos quais é elaborado o Memorial acertado del expediente para una Ley Agrária; a pedido da Sociedade Econômica de Madrid, Jovellanos analiza o documento e redige, entre 1788 e 1794, seu próprio parecer: Informe en el expediente de la Ley Agrária.

Gaspar Melchor de Jovellanos nasce em 1744 em Gijon, nas Astúrias. Pertence a uma familia nobre, de poucos recursos. Embora tenha se preparado para a carreira eclesiástica, 
acaba ingressando na magistratura. Em 1778, tendo adquirido a reputação de pensador progressista em Sevilha, onde ocupa seu primeiro cargo público, vai para Madrid e se insere no grupo mais "esclarecido" e poderoso da época, pois convive com o ministro Floridablanca, com o Conde de Campomanes, com Aranda e com Cabarrús. A morte de Carlos III dispersa essa brilhante equipe e esmorece o zelo reformista, sem que Jovellanos abandone sua produção intelectual ou suas realizações práticas, pois o Informe sobre la ley Agrária e a fundação do Instituto de Gijon são dessa época.

Em 1798 é nomeado Ministro da Justiça, graças a uma reviravolta política, mas só exerce o cargo por nove meses. Concentra sua atenção na reforma do ensino e no combate à Inquisição. Em 1801 é preso, permanecendo totalmente incomunicável durante algum tempo. Logo que melhoram as condições da prisão, recomeça a produzir e a escrever. Em 1808, com a abdicação do rei, é posto em liberdade e recusa o convite de José Bonaparte para ser Ministro do Interior, já que adere à luta contra o invasor em defesa da "santa e justa causa de minha pátria, que é a causa da honra, da justiça e da humanidade". 12 Volta brevemente ao poder como membro da Junta Central que governa o pais; em 1811 morre em sua cidade natal.

Em Jovellanos, como em tantos outros iluministas, destaca-se a abrangência verdadeiramente enciclopédica de sua personalidade: escreve com muita competência sobre economia, política, história, mineração, indústria, diversões públicas, educação, engenharia e direito, além de ser poeta e dramaturgo. Utiliza a poesia também para divulgar suas idéias políticas:

"De que serve

a classe ilustre, ou uma alta ascendência

Sem a virtude?

Se os privilegiados não servem

à Espanha:

Que a plebe intrépida,

a humilde plebe, irrompa e usurpe

- lustro, a nobreza, os títulos e honrarias,

que tudo venha abaixo, que não haja

nem classes nem estados. Se só a virtude

pode ser seu escudo e parapeito

Que tudo, sem ela, acabe e se confunda."13

Outra característica que compartilha com sua época é o 
espirito eminentemente prático: o progresso é o progresso material do país; o governo existe para tornar os homens felizes.14 Jovellanos não se perde em sonhos utópicos e quer conciliar as idéias e exigências novas com a tradição - desde que esta sirva para garantir as reformas ou para torná-las aceitáveis.

Sua produção intelectual revela essa preocupação, pois as memórias e pareceres - típicos, aliás, do momento cultural revelam a disposição de enfrentar a realidade, mergulhando nos problemas, censurando e criticando sempre que necessário. Preocupa-se com o fato dos "homens serem muito propensos a generalizar as verdades abstratas sem deter-se em aplicá-las".15

Apesar de ser homem de muita fé e católico praticante até - fim de sua vida, é muito atacado pela Igreja, e sobretudo pela Inquisição que o acusa de heresia, ateísmo, e simpatia pelas idéias de Voltaire; seus inimigos entre o clero chegam a montar uma verdadeira conspiração contra ele e contra a obra de que mais se orgulha, o Instituto de Gijón.

Seu pensamento sobre educação pode incorporar-se numa instituição concreta quando, após um enorme esforço, inaugura o Instituto que é, ao mesmo tempo, Escola de Ciências Exatas e Naturais, de navegação e de minerologia, adequadamente estabelecido em Gijón, um dos mais importantes portos do país e capital das Astúrias, grande centro mineiro.

Resumindo numa palavra seu pensamento político, Jovellanos é essencialmente um reformador; tem perfeita noção de que, para serem efetivas, as reformas propostas "devem ser simultâneas, sob risco de se exporem a maiores danos", como informa ao próprio rei. Propõe, na realidade, uma reforma estrutural da sociedade espanhola em seus aspectos sociais e econômicos. Para entender o sentido das reformas, é necessário compreender o significado, para ele, da palavra "constituição", que emprega no sentido de estrutura, definindo-a como "as bases, racional e efetivamente estabelecidas, da realidade de cada época, segundo as quais vai se articulando o ordenamento jurídico e político."16

Para ele a sociedade espanhoia de sua época é injusta, os privilégios da nobreza e do clero são desprovidos de sentido, e identifica com nitidez a base econômica desses privilégios: a propriedade da terra. A reforma da estrutura social (da 
"constituição") deve derivar de uma reforma "constitucional" (estrutural) da propriedade da terra: "se a terra for livre, também os homens que dela vivem o serão."17

É em torno desse conceito de estrutura que fundamenta seu reformismo, pois verifica que a mesma não é eterna $e$ rígida, tendo ao contrário, se revelado essencialmente dinâmica ao longo da história da Espanha. Sua tarefa como reformador é encaminhar a dinâmica social e econômica de forma a garantir uma evolução progressista e pautada pela razão, a fim de assegurar um desenvolvimento racional ao projeto de felicidade humana neste mundo.

Como é necessário ilustrar os povos para torná-los felizes, submete todas as consideraçōes de sua ação política a este axioma que fundamenta seu interesse pela educação em todos os niveis; esta preocupação é aliás típica do iluminismo e mais particularmente do iluminismo ibérico.

Em termos econômicos, defende os princípios fisiocratas de valorização do produto agrícola, o que faz muito sentido num pais às voltas com as conseqüências de trezentos anos do mercantilismo mais simplista, em sua versão monetarista. Nesse momento, inverte-se o prestígio dos metais preciosos trazidos à Europa, que de panacéia transformam-se em responsáveis pela crise espanhola; constata-se que o comércio colonial beneficiou sobretudo a França, a Holanda e a Inglaterra; valoriza-se em conseqüência a produção agrícola da metrópole: "O comércio... em Sevilha, onde as frotas o fixaram, levou atrás de si a riqueza de Castela, arruinou sua fábricas, despovoou sua vilas e instalou a miséria e a desolação em seus campos."18

Os inúmeros impostos, taxas, monopólios, e restriçōes ao plantio, que asfixiam a economia agricola espanhola, fazem Jovellanos aspirar pelos benefícios do liberalismo, segundo Adam Smith - a quem muito admira e por cujas idéias se bate. $\mathrm{Na}$ realidade, o "Informe" é uma longa exposição de princípios liberais, "apoiando-se num só princípio, extraído das leis primitivas da natureza e da sociedade, tão geral e fecundo que envolve em si todas as conseqüências aplicáveis, e tão constante que concluiu contra todas as falsas induções feitas a partir delas."19

Para uma melhor compreensão do pensamento político de Jovellanos, torna-se necessário frisar sua constante preocupa- 
ção com o bem comum, pois "no estado social é mais justo o homem que mede sua utilidade pelo bem moral"; 20 esta subordinação do interesse pessoal ao bem comum é, segundo Adam Smith, indispensável ao funcionamento do liberalismo. O Visconde Cairú, seu contemporâneo no Brasil, também salienta o embasamento moral da doutrina econômica do "laissez-faire": segundo Jovellanos, "a liberdade (de comércio) é fundada nos mais rigorosos princípios de justiça." 21

As reformas todas que preconiza são inspiradas por esse sentido de justiça social; ainda em relação à Mesta, afirma que "essa irmandade reune o poder e riqueza de poucos contra o desamparo e a necessidade de muitos", sendo "um conselho de senhores e monges convertidos em pastores." Ao propor que os preços sejam liberados, lembra "que as leis fixaram inalteravelmente o valor das hervas há um século... (e) as vicissitudes do comércio aumentaram as lãs a um preço tão espantoso, o que significa uma enorme injustiça." 22

Ao escrever o Informe, Jovellanos posiciona-se contra todas as forças sociais que dominam o Estado espanhol: contra a Igreja, ao defender a alienação dos bens de mão-morta; contra a Mesta, pregando a sua dissolução; contra a aristocracia, ao exigir o fim do morgadio e das isenções que permitem que se mantenha "ociosa". A reação aos interesses feridos é muito violenta: a obra é posta no índice de livros proibidos pela Igreja, o autor é perseguido pela Inquisição e pela Coroa, sendo encarcerado durante sete anos numa fortaleza na ilha de Maiorca. Sofre ainda uma tentativa de envenenamento, sendo um dos suspeitos o próprio primeiro-ministro Godoy.

A tempestade desencadeada contra Jovellanos atesta pois que essa reforma, exposta de forma tão clara e lúcida, desenvolvendo-se segundo um raciocínio tão simples que parece às vezes cândido, teria na realidade significado uma profunda transformação da sociedade espanhola. As vezes, no texto, ele parece transigir com certos princípios, mas o faz conscientemente, reconhecendo a impossibilidade de enfrentar abertamente a coligação de reacionários, conforme escreve em seus Diários. Também, é preciso não esquecer que o Informe é endossado pela Sociedade Econômica de Madrid, e que Jovellanos teme que sem seu apoio não possa divulgá-la.

Se as conseqüências pessoais são muito graves para o autor, cumpre registrar que, de certa forma, o governo deixa-se influenciar por sua argumentação. Em 1798, por ordem real, 
determina-se a alienação de todos os bens de raiz pertencentes a estabelecimentos de caridade, confrarias e outras fundações religiosas.

Como observa José Lage, um de seus editores, o Informe estabelece, pela primeira vez, de maneira sistemática e com conhecimentos teóricos, o estudo da realidade agrícola da Espanha, ou seja, o planejamento racional da economia. Segundo Jovellanos, "a economia social, ciência que se pode dizer deste século e talvez de nossa época, nunca informou as leis agrárias." 24 Assim, é muito mais que um relatório econômico, constituindo um projeto político de transformação social.

Ao "querer levantar a agricultura à sua maior prosperidade", ele verifica que "o cultivo acomodou-se sempre à situação política da nação." 25 Concede, como já foi dito, a ordem social de forma dinâmica, que vai se aperfeiçoando constantemente, o que explica a metodologia adotada em quase toda sua obra: a partir do histórico do problema, descreve a siutação atual, prevendo o futuro e os meios para realizá-lo.

A ideologia que fundamenta o Informe é declaradamente liberal; há momentos em que faz uma verdadeira apologia dessas idéias. Considera pois natural a tendência ao equilibrio e ao progresso; a tarefa do Estado deve se limitar a "remover os obstáculos que a natureza, a opinião e as leis opõem ao progresso"; a perfeição natural é melhor promovida pelo interesse individual, pois "a indústria se agita, circula e acode aonde lhe chama o interesse." 0 dever do rei, enquanto déspota esclarecido, é de assegurar essa prosperidade, "removendo com mão poderosa os estorvos que se opõem à prosperidade... ou ao interesse de seus agentes. $26^{\prime \prime} \mathrm{E}$, conseqüentemente, dedica a parte central do Informe a analisar esses estorvos, prevendo as felizes conseqüências que vão derivar de sua abolição.

Classifica os estorvos aos interesses particulares e públicos (que se identificam no bem comum) em políticos, ou derivados da legislação; morais, ou derivados da opinião; e físicos, ou derivados da natureza.

Jovellanos inicia o estudo desses obstáculos pelos políticos, ou seja, pelas leis e regulamentos que atrapalham o livre desenvolvimento da agricultura, agrupando-os por tipos de propriedade: inicialmente os problemas relativos às torres devolutas, mantidas para pastoreio e que devem ser vencidas ou 
arrendadas, dependendo da região. Assim, na Audalusia devem ser vendidas a "familias pobres e industriosas, lotes pequenos, mas que bastassem à subsistência da familia"27; o mesmo propõe em relação às terras pertencentes aos municipios, "já que é preciso multiplicar o interesse particular, multiplicando a propriedade individual, para dar um grande impulso à agricultura" 28 , e pede a derrogação das leis que impedem de cercar os campos cultivados com grãos. Estas providências vão de encontro aos interesses da Mesta, mas ele vai mais longe e pede "a inteira dissolução desta irmandade tão preponderante, a abolição de seus exorbitantes privilégios, a derrogação de suas injustas ordenanças e a supressão de seu tribunais opressivos.29 E acrescenta, justificando a medida pela grave injustiça social: "por que tolerar a reunião dos fortes contra os fracos?" 30

No capítulo seguinte, sobre a amortização, posiciona-se claramente contra a acumulação da propriedade territorial, invocando a autoridade dos artigos romanos. Entre as conseqüências nefastas das leis em vigor, aponta o encarecimento da terra, impossibilitando o acesso à mesma "o que torna impossivel favorecer com igualdade o interesse individual." 31

Ao estudar os bens de mão-morta encontra, na antiga legislação espanhola, proibições que impedem "às igrejas e mosteiros... aspirarem à propriedade territorial." Faz, entretanto, uma ressalva: sua posição não é contra os mosteiros em si, "cuja santidade respeita", mas contra a má influência que exercem na agricultura. A ação política que restabelecer a proibição de adquirir propriedade de mão-morta deve agir "não por ódio da Igreja, mas em favor do Estado, não para impedir o enriquecimento do clero mas para precaver o empobrecimento do povo." 32

Por seu posicionamento a respeito desta reforma, foi acusado de ingênuo ao propor que, "penetrado de respeito e confiança na sabedoria e virtude de nosso clero...., (sejam encarregados) os reverendos prelados das igrejas de promoverem, por si mesmos, a alienação de suas propriedades territoriais para que voltem às mãos do povo"; confia que "correriam ansiosos a prestar este serviço à pátria." $33 \mathrm{Se}$, no entanto, o clero se empenhar em reter suas terras, recomenda a proibição de adquirir propriedade.

Em relação às propriedades inalienáveis da aristocracia, recomenda a "abolição de todas as leis que permitem vincular 
a propriedade territorial," 34 embora respeitando os já existentes, mais um exemplo de que Jovellanos conhece a realidade de seu país. A prudência é a única possibilidade de sua sugestão ser aceita.

Outros obstáculos ao desenvolvimento da agricultura referem-se ao comércio dos produtos, "única propriedade do colono, (sendo) sagrada e digna de proteção, pois representa a recompensa de seu suor e fadiga." 35 Defende a liberdade de produzir e de comercializar os frutos da agricultura.

Ao tratar da política fiscal, reafirma, como fisiocrata que é, o "princípio que apresenta a agricultura como a primeira riqueza individual e da renda pública." 36 Pede uma reforma fiscal porque considera que a terra, "o mais abundante, o mais seguro manancial de riqueza pública e privada",37 é sempre preterida, na atenção do governo, pelo comércio e indústria.

Passa, em seguida, a descrever os estorvos morais ou derivados da opinião, e que podem ser resumidos na pouca importância atribuída à agricultura, "apresentada... como secundária"'38. Para reformar a mentalidade espanhola, que só valoriza o comércio e a indústria, propõe o "estudo da economia civil'"39, discorrendo sobre a necessidade do governo cuidar da parte técnica do cultivo; através da educação, deve comunicar tanto aos proprietários quanto aos lavradores os princípios teóricos à agricultura para suprir "a falta daquela instrução e conhecimentos que têm influência mais imediata na perfeição do cultivo" 40 .

O terceiro tipo de obstáculo, ou seja, os estorvos físicos e que exigem "esforço do interesse comum"41 são a falta de irrigação, de comunicações e de portos, determinando ainda como esses encargos devam ser repartidos entre o governo central, provincial e municipal ou conselhos.

As reformas propostas por Jovellanos teriam transformado profundamente a realidade espanhola. Em torno do explosivo problema agrário formam-se dois partidos, cada vez mais radicais. Quando em 1936 estala a Guerra Civil essa é uma questão fundamental para o povo espanhol.

Há duzentos anos que duas idéias de Espanha se enfrentam. Uma, tradicional, reacionária, isolacionista, resistente a qualquer transformação cultural ou econômica; a outra desenraizada, heterodoxa, europeista, partidária da mudança pela 
mudança. As duas Espanhas se opõem sem que uma possa incorporar a outra.

Mas resta uma terceira idéia de Espanha, a sonhada por Jovellanos, que teria acolhido o melhor das outras duas para forjar um ideal novo para o país.

NOTAS

1 SARRAILH, Jean. La España ilustrada en la segunda mitad del siglo XVIII. Mexico, Fondo de Cultura Economica, 1957.

2 CORTES, Antonio Luís. Reformas interiores. História de España; El reformismo borbónico. Mađrid,' 8: 51-52, dic. 1981.

3 GOMEZ DE LA SERNA, Gaspar. Les viajeros de la ilustración. Madrid, Alianza Editorial, 1974.

4 JOVELLANOS, Gaspar Melchor de. Diarios. Oviedo, Instituto de Estudios Asturianos, 1953-1956.

5 - Informe sobre la Ley Agraria. Madrid, Catedra, 1982. p. 225.

6 Vide, a respeito, o Discurso sobre el fomento de la industria popular, de Campomanes, publicado em 1774, em Madrid.

7 JOVELLANOS, op, cit. nota 5, p. 155.

8 Ibidem pp. 199 e 201.

9 Ibidem p. 209.

10 Ibidem p. 178.

11 Antes de Jovellanos, vários outros espanhóis haviam redigido pareceres teóricos, entre os quais Olavide; vide GOMEZ DE LA SERNA. Jovellanos, el español perdido. Madrid, Sala Editorial, 1975. pp. 347 a 351.

12 LAGE, José. El pensamiento de Jovellanos. In: JOVELLANOS, Gaspar Melchor de. Informe sobre la Ley Agraria. Madrid, Catedra, 1982.

13 FRAGA IRIBARNE, Manuel. El pensamiento conservador español. Barcelona. Planeta, 1981.

14 Jovellanos considera "a felicidade como meta e objetivo fundamental e o governo como provedor dela." LAGE, José. op. cit. p. 37.

15 JOVELLANOS, op. cit. nota 5, p. 264.

16 LAGE, op. cit., p. 39.

17 PALACiO ATARD, V. Los españoles de la nustración, Madriđ, Guadarrama, 1964. p. 62. Apud LAGE, op. cit. p. 39.

18 JOVELLANOS, op. cit. nota 5, p. 218.

19 Ibidem, p. 149.

20 Ibidem, p. 202.

21 Ibidem, p. 251.

22 Ibidem, pp. 203 e 205.

23 Seu temor é procedente pois, como vimos, os censores e a Inquísição mobilizam-se logo contra a obra.

24 JOVELLANOS, op. cit. nota 5, p. 163.

25 Ibidem, p. 155.

26. Ibidem, pp. 158 e 160.

27 Ibidem, p. 167.

28 Ibidem, pp. 171-172.

29 Ibidem, p. 205.

30 Ibidem, p. 209.

31 Ibidem, p. 210.

32 Ibidem, p. 220.

33 Ibidem, p. 226. 
34 Ibidem, p. 326.

35 Ibidem, p. 243.

36 Ibidem, p. 282.

37 Ibidem, p. 283.

38 Ibidem, p. 281.

39 Ibidem, p. 285.

40 Ibidem, p. 289.

41 Ibidem, p. 304.

41 Ibidem, p. 304.

\section{BIBLIOGRAFIA}

CORTES, Antonio Luís. Reforma Interiores. História de España; EI reformismo borbónico. Madrid, 8, dic. 1981.

FRAGA IRIBARNE, Manuel. EI pensamiento conservador español. Barcelona, Planeta, 1981.

GOMEZ DE LA SERNA, Gaspar. Los viajeros de la ilustración. Madrid, Alianza Editorial, 1974.

- Jovellanos, el español perdido. Madrid, Sala Editorial, 1975.

JOVEllanos, Gaspar Melchor de. Diarios. Oviedo, Instituto de Estudos Asturianos, 1953-1956.

Informe sobre la Ley Agraria. Madrid, Catedra, 1982.

PALACIO ATARD, V. Los españoles de la ilustración. Madríd, Guadarrama, 1964.

SARRAILH, Jean. La España ilustrada en la segunda mitad del siglo XVIII.

Mexico, Fondo de Cultura Econômica, 1957.

FUUNAÇ̃̃o Nacional Pró-Memória. 